\title{
The Effects of Work Environment Area on Job Stress and Heart Rate Variability-Focused on the Forest and City Area
}

\author{
Sujin Park ${ }^{1 *}$ and Mi Ae Jeong ${ }^{2}$ \\ ${ }^{1}$ Forest Welfare Division, Forest Policy and Economics Department, National Institute of Forest Science, Korea \\ ${ }^{2}$ Korea National Arboretum, Pocheon 11186, Korea
}

*Corresponding author: Sujin Park, Forest Welfare Division, Forest Policy and Economics Department, National Institute of Forest Science, Seoul, 02455, Korea

ARTICLE INFO

Received: 幽 November 01, 2020

Published: 幽 November 09, 2020

Citation: Sujin Park, Mi Ae Jeong. The Effects of Work Environment Area on Job Stress and Heart Rate Variability-Focused on the Forest and City Area. Biomed J Sci \& Tech Res 31(5)-2020. BJSTR. MS.ID.005154.

$\begin{array}{llr}\text { Keywords: Job Stress; Heart Rate } \\ \text { Variability; } & \text { Greenspace; } & \text { Work }\end{array}$ Environment

\section{ABSTRACT}

The study compared the worker's job stress and heart rate variability (HRV) between forest area and city area. This study deducted the application possibility of HRV as physiological index and influences of forest area on worker's job stress. One hundred eighty-eight researchers submitted to the following tests: A general questionnaire, the Korean Occupational Stress Scale (KOSS), and the heart rate variability tests. Low Frequency component (LF), High Frequency component (HF) in HRV values significantly were correlated with insufficient job control, organizational system subscales in job stress. Activity of the parasympathetic nervous system increased in $40 \mathrm{~s}$ workers at forest area than at city area. lnLF/HF of 40's workers as representatives of sympathetic nervous system in city area was higher than in forest area. job stress scores in forest area was lower than in city area. Based on this study, forest area near the work environment would effect on the worker's job stress mitigation. We suggest that the improvement of work environment by making forest area would be useful for the management of job stress.

Abbreviations: HRV: Heart Rate Variability; KOSS: Korean Occupational Stress Scale; LF: Low Frequency; HF: High Frequency; VLF: Very Low Frequency; EEG: Electroencephalogram

\section{Introduction}

Worker's job stress recently increases, according to organizational system and job intensity. Korea's labor productivity per worker in 2012 ranked $24^{\text {th }}$ among 34 OECD member countries, which was very low despite of working hours [1]. The phenomenon that productivity does not increase in proportion to working hours shows that the improvement of working environment and organizational system is necessary. As worker's job stress increases, not only labor productivity declines, but the quality of life and job satisfaction fall $[2,3]$, which consequently can affect national productivity. Job stress may cause brain cardiovascular system diseases and musculoskeletal disorders, as well as affect stress [4-7]. Not only individual stress control, but the place of work environment and organizational system's autonomy need to be encouraged and improved. An effort to enhance worker's health through job stress management has been continuously made. Job stress is indicated with psychological pressure and anxiety, and many studies on physiological indicators to verify physiological effects and manage worker's health are carried out.

In relation with this, heart rate variability (HRV) has been used a lot as an indicator correlated with stress. As physiological indicators for job stress and worker's health management, electroencephalogram (EEG), heart rate variability (HRV) and blood pressure have been used [8-11]. When job stress and the ease of physiological indicators measurement are taken into account, HRV is used most. Especially, HRV's utilization is high, because the possibility of cardiovascular disease development can be identified through HRV. The studies analyzing correlations between job stress and HRV reported that sympathetic and parasympathetic nerve 
systems activities showed a correlation with job stress [9,12]: HRV fell, according to the increase of job stress, and the HRV of workers who were exposed to chronic stress showed significant change [13]. In reality, there were some studies to analyze the correlation of HRV and job stress and use the correlation as a physiological indicator. A study of [8] reported the activities of parasympathetic and sympathetic nerve systems have mutual correlations. Based on such study cases, HRV is regarded as important in job stress management.

Because, HRV can be used as an indicator of cardiovascular disease development together with excessive stress, its utilization is high. However, the correlation of HRV and stress was not revealed, according to working conditions such as full time work or part time work. HRV can be an indicator showing physiological effect that may be received by human body, due to stress, through identifying the chronic imbalance of autonomic nerve system, which is a main cause of cardiovascular disease. The fact that the green environment helps health enhancement through stress reduction effect is well known. Studies backing up scientific grounds of it have been conducted as well. Existing studies have been mainly performed on stress reduction and the recovery of attention concentration and mental health. Green area may play a role as a managing medium of stress. Some campaign to use forests and urban parks for the management of job stress is also on the rise. Many studies on general public's psychological stability have been carried out. It was revealed that hands-on forest experiencing programs targeting the general public helped psychological stability including the relaxation of depression, anxiety and stress [14,15].

According to the study result of [16], the effect of easing job stress through forests can be confirmed in that job stress of workers working in a place of work, where they could see forests, was significantly lower than those working in a place of work, where they could see just urban view. As such, an effort to improve the place of work environment through green area like forests or parts is needed. There is a need to accumulate scientific grounds through health enhancement effect using physiological indicators, as well as psychological effect of the green area. In this regard, this study investigates the physical health characteristics of workers who have worked in the green area environment for a long time, and compares the change of HRV, a stress indicator, according to the place of work environment. This study analyzes a correlation between job stress and HRV to examine job stress and its physical effect and checks the effects of stress relaxation and physiological stability that forests located around the place of work can offer to workers. This study delves into psychological and physiological effects through job stress survey and HRV measurement targeting the workers in the places of work in a forest and a city.

\section{Materials and Methods}

\section{Subject}

This study investigated workers at three research institutes, according to the place of work environment, as study subjects. A state research institute located in the central part of Seoul consists of 105 personnel as an institute founded in 1997. Since its foundation, the institute was located in the central part of Seoul, and urban-type forest did not exist surrounding the institute, and a small scale urban natural park is located. The two state research institutes, located in Pocheon city, Gyeonggi province, were founded in 1999 and 2004, respectively. They have been located in Pocheon city, Gyeonggi province since their foundation till now, and Kwangnung forest is located around the institutes, and the access to the forest is easy. Kwangnung forest is the forest designated as UNESCO Biosphere Reserve in 2010, and the area of the forest and surrounding district is $24,465 \mathrm{~h}$. The study target is the experimental forests of the two institutes, of which area is 1,157ha and 1,072ha, respectively. They are located around the institutes (Figure 1).

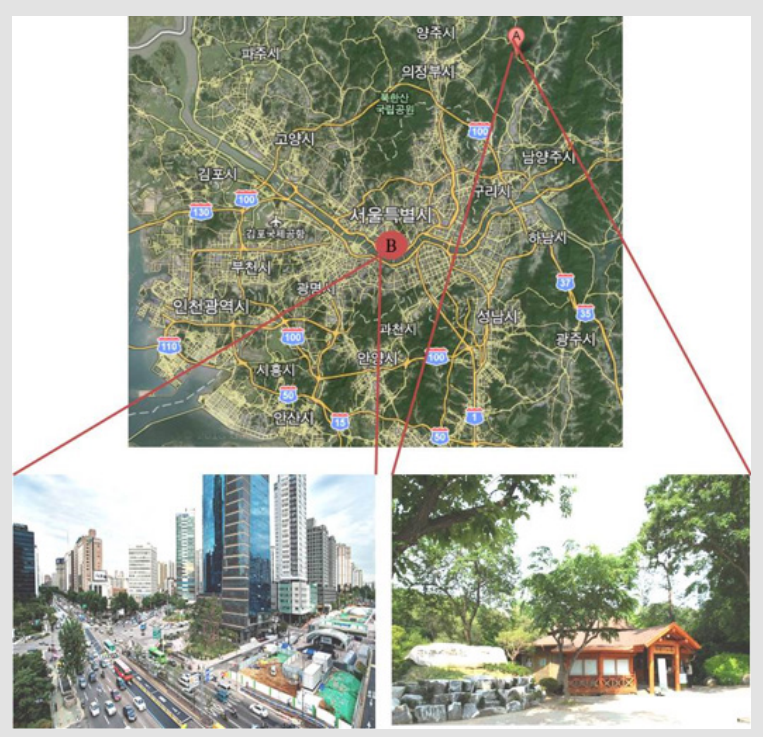

Figure 1: Locations of research areas (A: forest area, B: city area). 
This study examined the health status of workers through life habit and medical history survey, job stress examination and HRV test. The number of subjects in this study was 200, but the data of 188 subjects was used for analysis, except 12 people whose HRV outlier was measured. Ultimately, this study targeted 94 workers at the institute located in the central part of Seoul, and 84 workers at the two institutes located in Pocheon city. This study used each subject's HRV measurement data, life habit and medical history survey data and job stress survey data for the analysis.

\section{Survey Method}

Questionnaire Survey: This study carried out a questionnaire survey to identify subjects' general health status. The personal items included smoking and drinking habits, the status of indirect smoking, respiratory system and allergic disease symptoms and physical activity. As for the family member-related items, this study conducted the questionnaire survey on family member information, residential space, the status of chronic diseases, cancers and acute diseases, and symptoms.

Job Stress: As for the questionnaire of job stress measurement, the Koreans' job stress measuring tool developed by [12] as used, and the questionnaire consisted of physical environment, job demand, the lack of job autonomy, conflict of relationship, organizational system, inappropriateness of reward, job instability and corporate culture. The questionnaire was composed of 4-point scale, and reverse questions as well, according to the characteristics of questions. The score per item was calculated on the basis of Equation 1, and the total score of job stress was calculated on the basis of Equation 2. Higher score per item means higher job stress. The item of physical environment refers to the general physical environment affecting job stress, where workers are placed. The risk of work mode, air pollution and physical burden belong to the physical environment. The item of job demand means burden on job, and temporal pressure, workload increase, suspension during work, responsibility and excessive job burden belong to the job demand. The item of the lack of job autonomy means decision making right on one's duty, and the level of discretionary power utilization on duty.

Technical discretion and autonomy, job prediction possibility and job execution right belong to this item. The item of job instability refers to the degree of stability on one's job or duty. Job seeking opportunity and employment instability belong to this item. The item of conflict of relationship refers to interpersonal relationship including the lack of help or support from superiors or between peers within a company, and the support of peers, superior's support, and overall support belong to this item. The item of organizational system includes job stress factors such as organization's policy and operating system, organizational resources, conflicts within an organization, and rational communication. The item of inappropriateness of reward is to evaluate whether expected reward on duty is appropriate, and respect, internal motive and inappropriateness of expectation belong to this item. The item of corporate culture is to evaluate whether corporate culture's characteristics such as Korean-style collectivist culture, irrational communication system and informal corporate culture work as stress factors unlike the Western formal rationalism.

$<$ Equation 1>

Score of Item $=\frac{\text { actual score }- \text { score number }}{\text { expected maximum score-score number }}$

$<$ Equation 2>

Job stress total score $=\frac{\text { total score on score of 8items }}{8}$

Heart Rate Variability (HRV): HRV is a function representing neural activity related with human's autonomic nerve system. Therefore, a change that may cause the imbalance of autonomic nerve system psychologically can take place, if a person receives stress. Actually, the degree of stress can be inferred through HRV change. HRV was measured using a heart rate gauge (CANOPY9 plus, IEMBIO, Korea). HRV was measured, after removing jewelry worn by a subject to elevate the accuracy of examination, when the subject took 5-minute stable status in a sitting posture. By attaching the HRV gauge on the index finger of left hand, HRV was measured for five minutes. The HRV measurement results can be interpreted by dividing them into temporal domain and frequency domain. Temporal domain can be analyzed with SDNN (standard deviation of NN interval) and RMSSD (the square root of the mean squared differences of successive NN interval). SDNN is standard deviation of total heart rate gap, and RMSSD is the mean square root of the squared value of adjacent heart rate gap.

The frequency domain was analyzed targeting high frequency component (HF), low frequency component (LF) and very low frequency (VLF). This study also calculated TP (total power) and LF/HF ratio through which total HRV can be grasped and used the results for interpretation. LF is related with sympathetic nerve system, and HF is related with parasympathetic nerve system. $\mathrm{HF} / \mathrm{LF}$, which indicates relative activity of the sympathetic and parasympathetic nerve systems, is a representative index showing the instability of nerve system including stress. In addition, the balance and stability of autonomic nerve system can be checked through SDNN, which means the activity of overall autonomic nerve system. Because, the response of HRV changes, according to shortterm effect, it can be a variable with severe variability, according to the activities immediately before the measurement. This study, however, tried to control such a variability through taking an action such as the prohibition of smoking and drinking of the subjects from the previous day of the measurement. 


\section{Statistical Analysis}

This study comparatively analyzed the data of one institute located in Seoul, and two institutes located in Pocheon city. To test whether the differences of the age, gender, status of smoking and drinking, BMI and status of exercise, which are the general characteristics of the study subjects in the two areas, existed by area, this study conducted the chi-squared test. To analyze correlations between HRV item and job stress item, this study identified correlations between the items by calculating Pearson correlation coefficient $(\mathrm{p}<0.05)$. This study selected age showing a significant difference between the two areas among the medical

\section{Results}

\section{General Characteristics of Subjects}

Table 1: General characteristics of study subjects. history survey and life habit variables as covariance. Also, this study conducted the means comparison of job stress and HRV by the place of work environmental difference through an analysis of covariance.

This study compared means using the Student's t-test targeting the data of the two groups (institute located in Seoul and institutes located in Pocheon city) by job stress item and HRV item $(\mathrm{p}<0.05)$. A variance analysis on the health survey data of the institutes located in the forest area was performed through stratification by age. After the variance analysis, this study carried out a post-hoc analysis as well to analyze the differences by age group.

\begin{tabular}{|c|c|c|c|c|c|}
\hline \multirow{2}{*}{\multicolumn{2}{|c|}{ Variables }} & \multicolumn{2}{|c|}{ Forest $(n=94)$} & \multicolumn{2}{|c|}{$\operatorname{City}(n=94)$} \\
\hline & & \multirow{2}{*}{$\begin{array}{c}\text { Number } \\
20\end{array}$} & \multirow{2}{*}{$\begin{array}{c}\% \\
21.3\end{array}$} & \multirow{2}{*}{$\begin{array}{c}\text { Number } \\
17\end{array}$} & \multirow{2}{*}{$\begin{array}{c}\% \\
18.1\end{array}$} \\
\hline \multirow{4}{*}{ Age(year) } & $20-29$ & & & & \\
\hline & $30-39$ & 28 & 29.8 & 51 & 54.3 \\
\hline & $40-49$ & 25 & 26.6 & 20 & 21.3 \\
\hline & $>50$ & 21 & 22.3 & 6 & 6.4 \\
\hline \multirow{2}{*}{ Sex } & Male & 62 & 66 & 68 & 72.3 \\
\hline & Female & 32 & 34 & 26 & 27.7 \\
\hline \multirow{3}{*}{ Body Mass Index $\left(\mathrm{kg} / \mathrm{m}^{2}\right)$} & $<23$ & 35 & 37.2 & 27 & 28.7 \\
\hline & $23-25$ & 21 & 22.3 & 20 & 21.3 \\
\hline & $>25$ & 38 & 40.5 & 47 & 50 \\
\hline \multirow{2}{*}{ Smoking } & Current smoker & 21 & 22.3 & 31 & 33 \\
\hline & Non-smoker & 73 & 77.7 & 63 & 67 \\
\hline \multirow{2}{*}{ Alcohol Drinking (Frequency/Week) } & $>1$ & 32 & 34 & 51 & 54.3 \\
\hline & $<1$ & 62 & 66 & 43 & 45.7 \\
\hline \multirow{2}{*}{ Exercise } & Regular exercise & 34 & 36.2 & 28 & 29.8 \\
\hline & None & 60 & 63.8 & 66 & 70.2 \\
\hline
\end{tabular}

This study targeted 94 people in the forest area, and 94 people in the urban area. As for age bracket, those in $30 \mathrm{~s}$ and $40 \mathrm{~s}$ in the forest area took up $29.8 \%$ and $26.6 \%$, the highest ratios, respectively. In the urban area, those in 30 s accounted for $54.3 \%$, taking up most of the subjects. According to area, the age brackets of the subjects were significantly different $(\mathrm{p}<0.001)$. Concerning BMI (body mass index), the obese group's BMI was $40.5 \%$ in the forest area, and it was $50.0 \%$ in the urban area. In the forest area, the obese group's BMI was significantly low lower $(p<0.01)$. Regarding smoking ratio, $77.7 \%$ of the subjects answered as non-smokers in the forest area, and $67 \%$ in the urban area. As for the status of smoking in the two areas, no difference was revealed between the areas $(p=0.103)$. Regarding the number of drinking, less than one time was $66 \%$ in the forest area, which implies the number of drinking was small mostly. In the urban area, once and more a week was 54.3\%, which implies the number of drinking was higher. The number of drinking was relatively lower in the forest area than the urban area $(\mathrm{p}<0.01)$. For the status of exercise, the respondents saying they conducted regular exercise were $36.2 \%$ in the forest area, while they were $29.8 \%$ in the urban area. Therefore, the difference between the two areas was not significant in terms of the status of exercise $(\mathrm{p}=0.325)$ (Table 1).

\section{Correlation between HRV Indicator and Job Stress}

InHF, an indicator of HRV parasympathetic nerve system, and job autonomy showed a positive correlation, and the correlation efficient was 0.155 . Organizational system also showed a positive correlation, and the correlation index was 0.164. LFnorm and HFnorm revealed a negative correlation. RMSSD, an indicator explaining parasympathetic nerve system activity, showed 0.143 of correlation with job autonomy (Table 2). While HRV shows a significant correlation with job stress, the HRV indictor can be used as a physiological indicator that can sense stress caused at work. 
Table 2: Correlation coefficients among job stress and heart rate variability domains.

\begin{tabular}{|c|c|c|c|c|c|c|c|c|}
\hline & $\begin{array}{c}\text { Physical } \\
\text { Environment }\end{array}$ & Job Demand & $\begin{array}{c}\text { Insufficient Job } \\
\text { Control }\end{array}$ & $\begin{array}{c}\text { Interpersonal } \\
\text { Conflict }\end{array}$ & Job Insecurity & $\begin{array}{c}\text { Organizational } \\
\text { System }\end{array}$ & $\begin{array}{c}\text { Lack of } \\
\text { Reward }\end{array}$ & $\begin{array}{c}\text { Occupational } \\
\text { Climate }\end{array}$ \\
\hline SDNN & -0.008 & 0.001 & 0.045 & -0.008 & -0.046 & 0.116 & 0.049 & 0.046 \\
\hline InTP & -0.008 & -0.005 & 0.114 & -0.008 & 0.089 & 0.097 & 0.100 & 0.141 \\
\hline $\operatorname{lnVLF}$ & 0.044 & 0.039 & 0.085 & 0.044 & 0.070 & 0.090 & 0.109 & $0.178^{*}$ \\
\hline $\operatorname{lnLF}$ & -0.117 & -0.010 & 0.072 & -0.117 & 0.090 & 0.063 & 0.073 & 0.090 \\
\hline $\operatorname{lnHF}$ & -0.040 & -0.065 & $0.155^{*}$ & -0.040 & 0.111 & $0.164^{*}$ & 0.126 & 0.104 \\
\hline LFnorm & -0.104 & 0.073 & -0.133 & -0.104 & -0.045 & $-0.148^{*}$ & -0.085 & -0.036 \\
\hline HFnorm & 0.104 & -0.073 & 0.133 & 0.104 & 0.045 & $-0.148^{*}$ & 0.085 & 0.036 \\
\hline $\begin{array}{c}\text { LnLF/ } \\
\text { HF }\end{array}$ & -0.097 & 0.051 & -0.086 & -0.097 & -0.053 & -0.132 & -0.073 & -0.043 \\
\hline RMSSD & -0.081 & -0.028 & $0.143^{*}$ & -0.081 & -0.027 & 0.054 & 0.039 & 0.044 \\
\hline
\end{tabular}

Note: *: p-value<0.05

Comparison of Job Stress and HRV between Areas using

\section{Analysis of Covariance}

Since the age brackets of the subjects between the forest area and the urban area were different, this study carried out the analysis of covariance by setting age as covariance. As shown in Table 3, the HRV indicator between the forest and urban areas did not show significant differences. Meanwhile, significant differences were shown in the items of job demand, job autonomy, organizational system and inappropriateness of reward. Stress on job demand was higher in urban area ( $\mathrm{F}=16.196)$, and stress on job autonomy was higher in the workers (researchers) working at the forest areas ( $F=11.758)$. The research institute in the urban area was higher in stress, due to organizational system $(\mathrm{F}=16.229)$, and the urban area showed higher stress caused by the inappropriateness of reward $(\mathrm{F}=8.589)$. Although, no statistically high significant differences were revealed in the HRV indicator, significant differences were shown in job stress between the areas. Job stress in the forest area was confirmed to be slightly eased than in the urban area (Table 3).

Table 3: Analysis of covariance for job stress and heart rate variability adjusted by age.

\begin{tabular}{|c|c|c|c|c|}
\hline & Forest (n=94) & City (n=94) & F & p-value \\
\hline SDNN & $44.5 \pm 25.30$ & $42.3 \pm 19.20$ & 1.592 & 0.209 \\
\hline RMSSD & $36.6 \pm 26.40$ & $33.8 \pm 20.11$ & 0.661 & 0.199 \\
\hline LnTP & $6.4 \pm 0.90$ & $6.5 \pm 0.79$ & 0.151 & 0.835 \\
\hline LnVLF & $5.5 \pm 0.95$ & $5.5 \pm 0.87$ & 0.003 & 0.698 \\
\hline LnLF & $5.1 \pm 0.11$ & $5.3 \pm 0.09$ & 0.138 & 0.710 \\
\hline LnHF & $4.8 \pm 1.11$ & $4.9 \pm 1.03$ & 0.254 & 0.615 \\
\hline LFnorm & $57.3 \pm 17.50$ & $59.2 \pm 16.50$ & 0.254 & 0.615 \\
\hline HFnorm & $42.6 \pm 17.58$ & $40.7 \pm 16.50$ & 0.001 & 0.970 \\
\hline LnLFHF & $1.1 \pm 0.22$ & $1.1 \pm 0.17$ & 0.267 & 0.606 \\
\hline Physical Environment & $33.4 \pm 16.51$ & $34.2 \pm 13.81$ & 16.196 & 0.001 \\
\hline Job Demand & $44.5 \pm 22.52$ & $55.5 \pm 16.47$ & 11.758 & 0.001 \\
\hline Insufficient Job Control & $47.7 \pm 14.57$ & $42.5 \pm 14.18$ & 1.592 & 0.209 \\
\hline Interpersonal Conflict & $33.4 \pm 16.51$ & $34.2 \pm 13.81$ & 0.031 & 0.862 \\
\hline Job Insecurity & $43.5 \pm 13.32$ & $45.5 \pm 16.65$ & 16.229 & 0.001 \\
\hline Organizational System & $39.8 \pm 13.37$ & $48.4 \pm 12.62$ & 8.589 & 0.004 \\
\hline Lack of Reward & $39.5 \pm 14.69$ & $46.6 \pm 13.32$ & 3.407 & 0.067 \\
\hline Occupational Climate & $33.7 \pm 16.72$ & $40.0 \pm 17.45$ & & \\
\hline
\end{tabular}

Comparative Analysis of HRV Indicators and Job Stress by Age between Forest Area and Urban Area

According to the results of the analysis of covariance, significant differences of HRV indicators of the subjects between the forest and urban areas were not revealed; however, job stress was lower in four items (job demand, job autonomy, organizational system and the inappropriateness of reward) in the forest area than the urban area. For more in-depth comparative analysis, this study examined differences, according to area, with stratified data by age and gen- 
der. As shown in Table 4, HFnorm, used as the indicator of parasympathetic activity, was 36.8 in the case of workers in 40s working in the place of work in the urban area, and it was 51.0 for those in the forest area $(\mathrm{p}<0.05)$. InLF/HF, used for the indicator of sympathetic nerve system activity, was 1.1 in the case of workers in 40s working in the place of work in the urban area, higher than 0.99 of those in the forest area $(\mathrm{p}<0.05)$. As for job stress, job demand of workers in the urban area in their 20s was 50.9, higher than 30.0 of those in the forest area $(p<0.05)$. Workers in the urban area showed higher scores in organizational system and corporate culture than those in the urban area. However, the lack of job autonomy was higher in the workers in their 40 s and 50 s in the forest area (Table 4).

Table 4: One-way ANOVA for job stress and heart rate variability by region and age.

\begin{tabular}{|c|c|c|c|c|c|c|c|c|}
\hline Region & \multicolumn{4}{|c|}{ City } & \multicolumn{4}{|c|}{ Forest } \\
\hline Age(year) & $20 \mathrm{~s}(\mathrm{n}=17)$ & $30 s(n=51)$ & $40 s(n=20)$ & $50 s(n=6)$ & $20 s(n=20)$ & $30 \mathrm{~s}(\mathrm{n}=28)$ & $40 s(n=25)$ & $50 \mathrm{~s}(\mathrm{n}=21)$ \\
\hline SDNN & $45.4 \pm 9.57 \mathrm{ab}$ & $39.7 \pm 15.05 \mathrm{ab}$ & $52.2 \pm 30.83 a$ & $23.3 \pm 4.41 \mathrm{c}$ & $52.7 \pm 25.91 \mathrm{a}$ & $48.8 \pm 26.13 \mathrm{ab}$ & $41.8 \pm 25.53 \mathrm{ab}$ & $33.2 \pm 20.76 b c$ \\
\hline $\operatorname{lnTP}$ & $6.8 \pm 0.56 a$ & $6.6 \pm 0.75 a$ & $6.3 \pm 0.93 \mathrm{ab}$ & $5.5 \pm 0.61 c$ & $6.8 \pm 0.92 \mathrm{a}$ & $6.5 \pm 0.91 \mathrm{a}$ & $6.3 \pm 0.63 \mathrm{ab}$ & $5.8 \pm 0.91 b c$ \\
\hline $\operatorname{lnVLF}$ & $5.7 \pm 0.69 \mathrm{ab}$ & $5.7 \pm 0.80 \mathrm{ab}$ & $5.4 \pm 1.08 \mathrm{ab}$ & $4.6 \pm 0.76 c$ & $5.8 \pm 0.94 \mathrm{ab}$ & $5.8 \pm 0.96 a$ & $5.3 \pm 0.65 \mathrm{ab}$ & $5.1 \pm 1.09 \mathrm{bc}$ \\
\hline $\operatorname{lnLF}$ & $5.7 \pm 0.67 \mathrm{ab}$ & $5.3 \pm 0.87 \mathrm{ab}$ & $5.1 \pm 1.06 \mathrm{~b}$ & $4.2 \pm 0.97 c$ & $5.8 \pm 0.96 a$ & $5.2 \pm 0.98 \mathrm{ab}$ & $5.1 \pm 0.82 b$ & $4.3 \pm 0.94 \mathrm{c}$ \\
\hline $\operatorname{lnHF}$ & $5.2 \pm 0.70 \mathrm{a}$ & $5.0 \pm 1.11 \mathrm{ab}$ & $4.5 \pm 0.89 \mathrm{bc}$ & $3.9 \pm 0.59 c$ & $5.3 \pm 1.09 a$ & $4.7 \pm 1.14 \mathrm{ab}$ & $5.1 \pm 0.66 \mathrm{ab}$ & $3.9 \pm 1.07 \mathrm{c}$ \\
\hline LF_norm & $60.1 \pm 14.93 \mathrm{ab}$ & $57.6 \pm 16.62 \mathrm{ab}$ & $63.2 \pm 18.54 a$ & $56.5 \pm 12.02 \mathrm{ab}$ & $61.9 \pm 13.04 \mathrm{ab}$ & $60.5 \pm 18.90 \mathrm{ab}$ & $49.0 \pm 12.07 \mathrm{ab}$ & $59.3 \pm 22.23 \mathrm{ab}$ \\
\hline HF_norm & $39.8 \pm 14.93 \mathrm{ab}$ & $42.3 \pm 16.62 \mathrm{ab}$ & $36.8 \pm 18.54 b$ & $43.5 \pm 12.02 \mathrm{ab}$ & $38.0 \pm 13.04 \mathrm{ab}$ & $39.4 \pm 18.90 \mathrm{ab}$ & $51.0 \pm 12.07 \mathrm{a}$ & $40.6 \pm 22.23 \mathrm{ab}$ \\
\hline LnLF/HF & $1.1 \pm 0.13 \mathrm{ab}$ & $1.0 \pm 0.16 \mathrm{ab}$ & $1.1 \pm 0.22 \mathrm{a}$ & $1.0 \pm 0.13 \mathrm{ab}$ & $1.1 \pm 0.13 \mathrm{ab}$ & $1.1 \pm 0.22 \mathrm{ab}$ & $0.9 \pm 0.09 b$ & $1.1 \pm 0.35 \mathrm{a}$ \\
\hline RMSSD & $34.9 \pm 11.89 \mathrm{ab}$ & $35.2 \pm 23.24 \mathrm{ab}$ & $34.2 \pm 18.67 \mathrm{ab}$ & $16.6 \pm 4.50 \mathrm{c}$ & $41.7 \pm 26.07 \mathrm{ab}$ & $36.5 \pm 24.97 \mathrm{ab}$ & $42.4 \pm 31.56 a$ & $24.4 \pm 18.91 b c$ \\
\hline $\begin{array}{c}\text { Physical } \\
\text { Environment }\end{array}$ & $30.0 \pm 14.57 \mathrm{abc}$ & $37.9 \pm 15.26 a$ & $31.1 \pm 21.79 \mathrm{abc}$ & $22.2 \pm 22.22 \mathrm{bc}$ & $27.2 \pm 17.46 \mathrm{abc}$ & $35.3 \pm 17.64 \mathrm{a}$ & $33.7 \pm 20.40 \mathrm{ab}$ & $20.1 \pm 15.16 \mathrm{c}$ \\
\hline Job Demand & $50.9 \pm 17.33 \mathrm{ab}$ & $54.6 \pm 17.17 \mathrm{ab}$ & $62.0 \pm 13.78 \mathrm{a}$ & $48.6 \pm 14.10 \mathrm{ab}$ & $30.0 \pm 17.13 c$ & $51.4 \pm 23.84 \mathrm{ab}$ & $49.3 \pm 20.00 \mathrm{ab}$ & $42.4 \pm 22.84 \mathrm{bc}$ \\
\hline $\begin{array}{c}\text { Insufficient Job } \\
\text { Control }\end{array}$ & $51.7 \pm 10.41 \mathrm{a}$ & $42.3 \pm 12.77 \mathrm{abc}$ & $35.0 \pm 14.32 \mathrm{c}$ & $36.6 \pm 20.11 \mathrm{bc}$ & $51.3 \pm 16.90 \mathrm{a}$ & $48.3 \pm 10.36 a$ & $45.3 \pm 13.05 \mathrm{ab}$ & $47.3 \pm 18.60 \mathrm{a}$ \\
\hline $\begin{array}{l}\text { Interpersonal } \\
\text { Conflict }\end{array}$ & $29.9 \pm 13.52 a$ & $35.4 \pm 14.98 \mathrm{a}$ & $34.1 \pm 13.21 \mathrm{a}$ & $34.7 \pm 8.19 \mathrm{a}$ & $29.5 \pm 11.93 a$ & $35.4 \pm 19.32 \mathrm{a}$ & $30.6 \pm 14.57 \mathrm{a}$ & $37.7 \pm 18.37 a$ \\
\hline Job Insecurity & $48.0 \pm 18.62 \mathrm{a}$ & $48.5 \pm 16.01 \mathrm{a}$ & $38.6 \pm 15.55 \mathrm{ab}$ & $33.3 \pm 14.05 b$ & $43.8 \pm 15.70 \mathrm{ab}$ & $47.8 \pm 15.59 a$ & $41.8 \pm 9.94 \mathrm{ab}$ & $40.4 \pm 10.11 \mathrm{ab}$ \\
\hline $\begin{array}{l}\text { Organizational } \\
\text { System }\end{array}$ & $47.6 \pm 11.41 \mathrm{ab}$ & $50.5 \pm 12.52 \mathrm{a}$ & $43.9 \pm 12.51 \mathrm{abc}$ & $43.6 \pm 16.33 \mathrm{abc}$ & $34.7 \pm 13.11 \mathrm{c}$ & $44.0 \pm 17.32 \mathrm{abc}$ & $39.8 \pm 9.10 \mathrm{bc}$ & $39.0 \pm 11.02 b c$ \\
\hline Lack of Reward & $45.7 \pm 12.65 \mathrm{ab}$ & $49.3 \pm 14.08 a$ & $40.2 \pm 9.47 \mathrm{ab}$ & $43.5 \pm 15.07 \mathrm{ab}$ & $36.1 \pm 15.02 b$ & $44.8 \pm 17.43 \mathrm{ab}$ & $38.6 \pm 10.57 b$ & $36.7 \pm 13.99 b$ \\
\hline $\begin{array}{l}\text { Occupational } \\
\text { Climate }\end{array}$ & $42.1 \pm 19.42 \mathrm{a}$ & $42.4 \pm 17.42 \mathrm{a}$ & $33.3 \pm 13.78 \mathrm{ab}$ & $29.1 \pm 16.45 b$ & $29.1 \pm 15.17 b$ & $42.2 \pm 16.65 \mathrm{a}$ & $32.3 \pm 51.08 \mathrm{ab}$ & $28.5 \pm 17.19 b$ \\
\hline
\end{tabular}

Note: $a, b, c:$ Each alphabet means the age group as a same group $(\mathrm{p}<0.05)$.

\section{Discussion}

\section{Correlation between HRV Indicator and Job Stress}

In HRV, a correlation was shown between lnLF, revealing parasympathetic nerve system, and job stress [8,9]. Through the correlation between job stress and HRV, this study found out a correlation between psychological stress and physiological response. Worker's psychological stress may affect human body physiologically. Although, there can be difficulties in examining the causal relationship of physiological change to human, due to stress, a physiological indicator will play a role in sensing physiological change that may be caused, because of accumulated stress, in advance. In the results of this study, job stress and HRV test can be applied in linkage mutually, because the job stress and HRV tests were carried out in the same time slot. The HRV indicator showed a significant change, according to job stress, and the changes of $\mathrm{HF}$ and LF were remarkable. The study [17] reported that working factors in a workplace affect the HRV indicator. This study also confirmed the HRV indicator is useful for examining psychological and physiological changes, according to the working environment. Finding physiological index that can be continually measured at the workplace concerned for job stress management and offering the facilities and services to relax job stress can be measures to contribute to long-term working environment management.

\section{Comparison of Job Stress and HRV Indicator between Areas using Analysis of Covariance}

As a result of variance analysis on age as covariance, the significant differences of HRV between areas were not revealed. However, differences in psychological stress seem to be found, given that clear differences were revealed in job stress, according to the place of work environment. This study examined HRV indicator's change through stratification of each area's subject group, according to age that is a variable affecting HRV in order to identify differences on psychological stress and the HRV indicator. In some age brackets, differences of the HRV indicator were shown, according to area. Especially, HF indicating parasympathetic nerve activity was higher, and InLF/HF was lower in the forest environment than the urban 
environment. Using HRV, overall autonomic nerve system activity can be judged through SDNN change, which is a temporal domain indicator, and the changes of $\mathrm{HF}$ and LF, which are frequency domain. The HRV indicator change generally revealed in stress state causes the imbalance of autonomic nerve system by reduction of autonomic nerve system activity, due to the decrease of SDNN and LF's relative increase compared with HF component $[18,19]$. In the case of workers in $40 \mathrm{~s}$, stable stress state was revealed by showing higher HF component than LF component in the forest area.

Higher HF component also means activated parasympathetic nerve, and this phenomenon can be a physiological response indicated according to positive emotion [20]. From such a result, job stress scores of workers in the place of work located in the forest area were lower overall, and therefore, low level of stress can be found out in the forest area than urban area. In relation with the HRV indicator, an indicator revealing the stable level of stress was activated. According to [16], job satisfaction rose, and jobs stress decreased by looking at forest view, when forest existed around the place of work. Several studies showed some cases identifying that short-term experience activities in a forest affected the ease of stress through psychological stability effect $[14,15]$. As such, shortterm activities in a forest show psychological stability effect, and worker's workplace location can have an effect on worker's stress and physiological change, according to this study. Consequently, the findings in this study show that labor productivity can be enhanced through the ease of worker's job stress by securing green area space in shaping worker's place of work environment. For the longterm, the role of forest to enhance worker's health is conjected to be important.

\section{Conclusion}

This study was performed to identify the effect of the place of work environment on worker's job stress and HRV. As a result of analyzing correlations between indicators to grasp the utilization of HRV as a human physiological indicator on job stress, the HRV indicator showed significant correlations between job stress and the lack of job autonomy and organizational system. To find out interaction between indicators, further studies on correlations between HRV and job stress are judged to be required. The parasympathetic nerve system activity of the workers in 40s, whose place of work is around a forest was higher than that of those in the urban area, and lnLF/HF showing sympathetic nerve activity was found higher in workers in 40s whose place of work located in the urban area than the forest area. Job stress was lower in the workers in the place of work located in the forest area than urban area in most items. To use the HRV indicator to manage job stress, a further study to monitor the place of work environment, organizational system and HRV change seems to be needed. The existence of a forest around the place of work can cause the differences of job stress and the HRV indicator. Therefore, placing green area to the place of work environment can contribute to the place of work environment improvement. The place of work environment improvement is expected to show the health enhancement effect of workers.

\section{References}

1. (2013) Korea Productivity Center, International comparison of labor productivity. Korea Productivity Center, pp. 353.

2. Lee K, Heo H, Kim D, Kim I, Kim S, et al. (2009) The factors related to health-related quality of life(HRQOL), and correlation between occupational stress and HRQOL among municipal fire officers in Incheon. Korean Journal of Occupation Environmental Medicine 21(3): 267-275.

3. ES Jeon, KS Lee, SY Lee, JH Yu, AR Hong (2009) The relationship between job stress and quality of life for hospital workers by type of employment. Korean Journal of Occupation Environmental Medicine 21(1): 28-37.

4. SY Choi, HS Kim, TH Kim, DH Park (2005) A study on job stress and MSDs (musculoskeletal disorders) of workers at automobile manufacturing industry. Journal of KOSOS 20(3): 202-211.

5. SB Koh, SJ Chang, JK Park, JH Park, DK Son, et al. (2005) Occupational stress and risk factors for cardiovascular diseases. Korean Journal of Occupation Environmental Medicine 17(3): 186-198.

6. CK Hwang, SB Koh, SJ Chang, CY Park, BS Cha, et al. (2007) Occupational stress in relation to cerebrovascular and cardiovascular disease: Longitudinal analysis from the nsdsos project. Korean Journal of Occupation Environmental Medicine 19(2): 105-114.

7. DS Ko, DJ Lee, TS Ko (2013) Changes in job stress, self-efficacy, depression and health-related quality of life according to the degree of musculoskeletal symptoms for white-collar workers. Journal of the Korea Academia-Industrial cooperation Society 14(6): 2935-2944.

8. MN Ha, JY Kim, JS Par, HK Chung (2001) Influence of shiftwork duration on blood pressure and heart rate variability in short rotating 8-hour shiftworkers. Korean Journal of Occupation Environmental Medicine, 13(2): 180-189.

9. KJ Yoon, MN Ha, KJ Young, S Lee, HJ Im, et al. (2002) The effects of job stress on the autonomic nerve activity of workers in manufacturing industry. Korean Journal of Occupation Environmental Medicine 14(2): 280-287.

10.SS Ahn (2009) The effect of the jun-yeol psychological program on job stress : A case study on the workers engaged in the disabled welfare facilities. Journal of special of Education \& Rehabilitation Science 48(1): 47-75.

11. KT Kim, CH Lee (2010) Study on the difference of body composition, metabolic factor, and blood components according to job form and stress level for security guard workers. Korean Security Science Review 22: $1-14$.

12. SJ Chang, SB Koh, HR Choi, JM Woo, BS Cha, et al. (2004) Job stress, heart rate variability and metabolic syndrome. Korean Journal of Occupation Environmental Medicine 16(1): 70-81.

13. L Tsaneva, R Dukov (2004) Correlations between certain hearing changes and vegetative balance in miners. Central European Journal of Public Health 12(1): 49-52.

14.JH Song, WS Shin, PS Yeoun, MD Choi (2009) The influence of forest therapeutic program on unmarried mothers' depression and selfesteem. Journal of Korean Forest Society 98(1): 82-87.

15. DJ Kim, SS Lee (2014) Effects of forest therapy program in school forest on employment stress and anxiety of university students. Journal of Korean Society People Plants and Environment 17(2): 107-115.

16. WS Shin (2007) The influence of forest view through a window on job satisfaction and job stress. Scandinavian Journal of Forest Research 22(3): 248-253. 
17. MJ Son, YK Kim, YS Bum, JH Kim, DM Kang, et al. (2008) Chronic and acute effects of work-related factors on heart rate variability. Korean Journal of Occupation Environmental Medicine 20(4): 314-325.

18. W Kim, JM Woo, JH Chae (2005) Heart rate variability in psychiatry. Journal of Korean Neuropsychiatry Association 44(2): 176-184.

\section{ISSN: 2574-1241}

DOI: 10.26717/BJSTR.2020.31.005154

Sujin Park. Biomed J Sci \& Tech Res

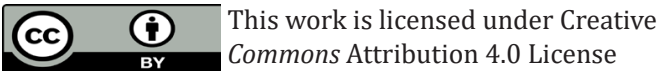

Submission Link: https://biomedres.us/submit-manuscript.php
19. KS Jeong, BC Lee, WS Choi, BT Kim, JM Woo, et al. (2006) A study on the positive emotional effects on heart rate variability. Korean Journal of Occupation Environmental Medicine 9(2): 111-118.

20.SY Kim, HW Seo, JW Kim, SY Chung (2011) Relationship between heart rate variability and BDI, STAI, and STAXI. Journal of Oriental Neuropsychiatry 22(4): 87-100.

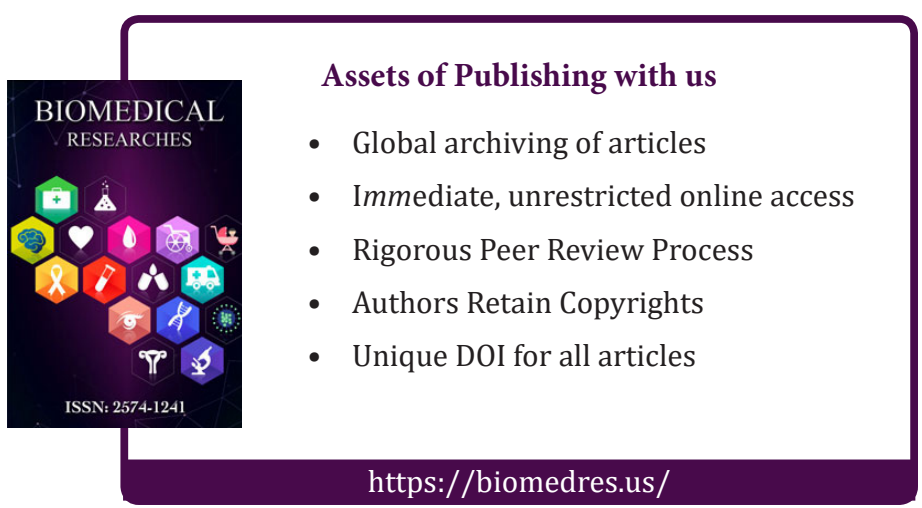

